\title{
Air pollution and mortality in a cohort of patients with chronic obstructive pulmonary disease: a time series analysis
}

\author{
Judith Garcia-Aymerich, Aurelio Tobías, Josep Maria Antó, Jordi Sunyer
}

Respiratory and Environmental Health Unit, IMIM,

Barcelona, Spain

J Garcia-Aymerich

A Tobías

J M Antó

J Sunyer

Department of
Experimental and
Health Sciences,
Universitat Pompeu
Fabra, Barcelona,
Spain
J M Antó
Correspondence to:
Dr J Sunyer, Respiratory and
Environmental Health
Research Unit, Institut
Municipal d'nnestigació
Mèdica (IMIM), Doctor
Aiguader 80, E-08003
Barcelona, Catalonia, Spain.
Accepted for publication
31 May 1999

Many studies have shown an association between current daily levels of air pollution and daily mortality by respiratory and cardiovascular causes in the general population. ${ }^{1}$ However, the weak associations observed and the ecological nature of the exposure to air pollutants have created some doubts about plausibility of a causal relation. Specificity, which increases the plausibility of causal inference although its lack does not negate it, could be increased using a population more susceptible a priori. $^{2}$ Hence, we assessed the association between daily levels of air pollutants and daily mortality in a cohort of chronic obstructive pulmonary disease (COPD) patients in Barcelona for the years 1985 to 1989 . We hypothesised that patients with COPD are more likely to die after increased exposure to urban air pollution than the general population. ${ }^{2}$

\section{Methods}

All patients attending emergency room services for either asthma or COPD were recruited during the years 1985 to 1989 in Barcelona. Vital status was obtained through record linkage of the people of the cohort with the Catalonia Mortality Registry for the years 1985 to $1989 .{ }^{3}$ A total of 9987 people (of the 15517 in the initial cohort) had a diagnosis of COPD, 3245 of whom died in the period 1985 to 1989 and were used in this analysis. Cardiovascular mortality refers to codes 390 to 459 and respiratory mortality to codes 460 to 519 of the International Classification of Diseases (ICD-9).

Daily information on levels of black smoke, sulphur dioxide $\left(\mathrm{SO}_{2}\right)$, nitrogen dioxide $\left(\mathrm{NO}_{2}\right)$, ozone $\left(\mathrm{O}_{3}\right)$, temperature and relative humidity was collected from the city network. ${ }^{4}$

Poisson regression time series models were fitted for each pollutant (in a log-linear form) and each different category of mortality following the APHEA methodology ${ }^{5}$ and adding the natural logarithm of the number of subjects at risk (that is, those still alive) as an offset. The analyses were done using Stata, release 5.0.

\section{Results}

The daily mean number of deaths was 1.8 for all causes mortality, ranging from 0 to 9 , and 0.7 (0 to 5) and 0.5 (0 to 4 ) for respiratory and cardiovascular mortality, respectively. Levels of air pollutants have been published elsewhere. ${ }^{4}$

Table 1 shows the estimated association between air pollutants and mortality in our cohort compared with the estimates for the general population in Barcelona. Associations between one hour maximum of $\mathrm{SO}_{2}, 24$ hours average of $\mathrm{NO}_{2}$ and one hour maximum of $\mathrm{NO}_{2}$, and mortality among COPD patients were stronger than associations obtained with the general population, mainly related to respiratory diseases.

\section{Discussion}

Daily mortality in COPD patients is related to daily levels of all six pollutants, for all, respiratory and cardiovascular causes. This association is stronger than in the general population only for peaks of $\mathrm{SO}_{2}$ and daily means and peaks of $\mathrm{NO}_{2}$. Particles, measured as black smoke, and daily mean of $\mathrm{SO}_{2}$, the pollutants classically associated with mortality, ${ }^{6}$ showed similar or weaker associations for COPD patients than for the general population. Changes in the profile of urban air pollutants, with a currently more pronounced photochemical component, could explain in part these effects.

Caution is necessary when comparing with the general population given the small range of

Table 1 Estimated relative risks and 95\% confidence limits for total, respiratory and cardiovascular mortality for an increase of $50 \mu \mathrm{g} / \mathrm{m}^{3}$ in air pollutants, in the general population and a cohort of COPD patients in Barcelona

\begin{tabular}{|c|c|c|c|c|c|c|c|c|c|c|c|c|}
\hline & $\begin{array}{l}\text { Black smoke } \\
24 \mathrm{~h}\end{array}$ & lag & $\mathrm{SO}_{2} 24 h$ & lag & $\mathrm{SO}_{2} 1 \mathrm{~h}$ & lag & $\mathrm{NO}_{2} 24 h$ & lag & $\mathrm{NO}_{2} 1 \mathrm{~h}$ & lag & $\mathrm{O}_{3} 1 \mathrm{~h}$ & lag \\
\hline \multicolumn{13}{|l|}{ Total mortality } \\
\hline \multirow[t]{2}{*}{ general population ${ }^{\star}$} & 1.056 & $0-3$ & 1.078 & $0-3$ & 1.013 & 1 & 1.043 & $0-3$ & 1.017 & 1 & 1.024 & 5 \\
\hline & $1.027,1.087$ & & $1.041,1.116$ & & $1.004,1.021$ & & $1.011,1.076$ & & $1.006,1.027$ & & $1.006,1.042$ & \\
\hline \multirow[t]{2}{*}{ COPD } & 1.023 & $0-2$ & 1.045 & $0-2$ & 1.036 & 2 & 1.145 & $0-2$ & 1.023 & 2 & 1.040 & 3 \\
\hline & $0.915,1.145$ & & $0.914,1.193$ & & $0.999,1.074$ & & $1.006,1.304$ & & $0.975,1.115$ & & $0.953,1.134$ & \\
\hline \multirow{3}{*}{$\begin{array}{l}\text { Respiratory mortality } \\
\text { general population }\end{array}$} & & & & & & & & & & & & \\
\hline & 1.051 & $0-3$ & 1.062 & $0-1$ & 1.017 & 0 & 1.043 & $0-1$ & 1.013 & 0 & 1.035 & 5 \\
\hline & $0.975,1.134$ & & $0.989,1.141$ & & $0.994,1.039$ & & $0.970,1.122$ & & $0.983,1.044$ & & $0.981,1.092$ & \\
\hline \multirow[t]{2}{*}{ COPD } & 1.071 & $0-2$ & 1.041 & $0-2$ & 1.050 & 2 & 1.161 & $0-2$ & 1.084 & 2 & 1.057 & 3 \\
\hline & $0.903,1.271$ & & $0.849,1.276$ & & $0.993,1.110$ & & $0.944,1.428$ & & $1.005,1.169$ & & $0.921,1.214$ & \\
\hline \multirow{3}{*}{$\begin{array}{l}\text { Cardiovascular mortality } \\
\text { general population }{ }^{\star}\end{array}$} & & & & & & & & & & & & \\
\hline & 1.059 & $0-3$ & 1.091 & $0-3$ & 1.016 & 1 & 1.031 & $0-3$ & 1.019 & 1 & 1.029 & 1 \\
\hline & $1.019,1.101$ & & $1.040,1.144$ & & $1.005,1.028$ & & $0.988,1.076$ & & $1.004,1.034$ & & $1.004,1.054$ & \\
\hline COPD & $\begin{array}{l}0.908 \\
0.733,1.124\end{array}$ & $0-2$ & $\begin{array}{l}1.035 \\
0.808,1.325\end{array}$ & $0-2$ & $\begin{array}{l}1.067 \\
0.999,1.140\end{array}$ & 3 & $\begin{array}{l}1.056 \\
0.827,1.348\end{array}$ & $0-2$ & $\begin{array}{l}1.032 \\
0.942,1.130\end{array}$ & 3 & $\begin{array}{l}1.011 \\
0.858,1.192\end{array}$ & 3 \\
\hline
\end{tabular}

*Partially published in reference 4 . 
daily deaths that led to wide confidence intervals. This also precluded an adequate fit using time series models, according to the analysis of residuals. Results did not change using generalised additive models (not shown).

Respiratory mortality showed stronger associations for COPD patients than for the general population for all pollutants excepting averages of $\mathrm{SO}_{2}$, while cardiovascular mortality did so only for peaks of $\mathrm{SO}_{2}$ and the two measures of $\mathrm{NO}_{2}$. This suggests that the susceptibility of COPD patients to air pollution is mainly related to their respiratory condition.

Funding: supported in part by grants from the Fondo Investigaciones Sanitarias, Madrid, Spain (FIS, no 96/0042-01), and the Generalitat de Catalunya (CIRIT 1997 SGR 00079). Judith Carcia-Aymerich has a fellowship from Instituto de Salud “Carlos III" (no exp 4365).
Conflicts of interest: none.

1 Zmirou D, Schwartz J, Saez M, et al. Time-series analysis of air pollution and cause-specific mortality. Epidemiology 1998;9:495-503.

2 Schwartz J. What are people dying of on high air pollution days? Environ Res 1994;64:26-35.

3 Sunyer J, Anto JM, McFarlane D, et al. Sex differences in mortality of people who visited emergency rooms for asthma and chronic obstructive pulmonary disease. $A m \mathcal{F}$ Respir Crit Care Med 1998;158:851-6.

4 Sunyer J, Castellsague J, Saez M, et al. Air pollution and mortality in Barcelona. I Epidemiol Community Health 1996;50:S76-80.

5 Katsouyanni K, Schwartz J, Spix C, et al. Short term effects of air pollution on health: a European approach using epidemiologic time series data: the APHEA protocol. $f$ Epidemiol Community Health 1996;50:S12-18.

6 Katsouyanni K, Touloumi G, Spix C, et al. Short-term effects of ambient sulphur dioxide and particulate matter on mortality in 12 European cities: results from time series data from the APHEA project. Air Pollution and Health: a European Approach. BMF 1997;314:1658-63. 